\title{
THE BENEFIT OF CACAO PEEL'S LIGNIN AS AN ADHESIVE USING MULTI FUNCTION EXTRACTOR
}

\author{
Mu'tasim Billah ${ }^{1}$, Titi Susilowati ${ }^{2}$, Susilowati ${ }^{3}$, and Diah Hari Suryaningrum ${ }^{4}$ \\ University of Pembangunan Nasional"Veteran" Jawa Timur, Surabaya, Indonesia \\ E-Mail: tasimbillah60@yahoo.co.id, tasimbillah60@gmail.com
}

\begin{abstract}
Lignin of Cacao Peel can be used as lignin adhesive by cooking process with sodium hydroxide liquid in the multifunction extractor. The benefit of this study is to minimize the waste of cacao peel that is plentiful. Cacao peel was cleaned then dried and pounded. Powder of cacao peel $(200 \mathrm{gr})$ was cooked with water at $70{ }^{\circ} \mathrm{C}$ for an hour and then leaked. Sodium hydroxide liquid $1000 \mathrm{~mL}$ is used in various concentration (\%); i.e : 8,10,12 and 18 for different times $(60,90,120$ and 180 minutes). After that, the mixture of liquid and solid cooking was separated to get lignin and its deposit was disposed. The black liquor was added with water until it reached a $\mathrm{pH}$ of 8-9. The sedimentation process was then performed by adding Chloride acid $10 \%$ until pH reached 2-3, during 8-10 hours. The Lignin formed is separated and dried. Lignin powder ( $5 \mathrm{gr}$ ) was mixed with $2.5 \mathrm{gr}$ resorcinol and $10 \mathrm{~mL}$ of formaldehyde solution, agitated by adding $\mathrm{NaOH} 10 \%$ and $50 \%$, respectively, each of that $20 \mathrm{~mL}$, until lignin gum is formed. The result showed that $600 \mathrm{~mL}$ of black liquor provided $29.8 \mathrm{gr}$ lignin powder and lignin adhesive. It's adhesive capacity is $3.54 \mathrm{~kg} / \mathrm{sq} . \mathrm{Cm}$ and the color is near to cacao peel's color.
\end{abstract}

Keywords: Cacao peel, black liquor, lignin adhesive.

\section{INTRODUCTION}

One ton of cacao seed produces approximately 10 tons of fresh cacao peel, resulting in generating piles of cacao peel's waste. One of the methods to solve the problem is processing cacao peel to become lignin products which have a sale value that is beneficial for humans. Lignin is the primary component in chemical's wood beside cellulose and hemicellulose. The existence of lignin is plentiful in the world and regarded as the second polymer organic component. Lignin has been studied as an adhesive for more than 100 years, but there are only a few industrial applications. The reason for the current interest is the high availability and low price of lignin, (Hemmila, et.al., 2013).

According to Research and Development Center in Department of Forestry, as much as $20-60 \%$ of production cost in wood industries was used to buy adhesives. The industries that depend on this gum i.e.: plywood industry, particle board industry, vinyl, fiberboard industry, and connected board. Most of the adhesives were obtained from petroleum that is nonrenewable. Lignin as an adhesive has been the subject of several reviews (Rowell, 2005) (Pizzi, 2006) (Hu. et al., 2011) (Imam. et al., 2012) (Mankar. et al., 2012).

The simplest way to use lignin as an adhesive is to use it as a partial replacement for phenol in PF resins. A lot of work has been done on this for different types of lignin and in various percentages and $\mathrm{P} / \mathrm{F}$ ratios, and it can be concluded that for applications that require fast curing, the use of unmodified lignin is not cost-effective (Danielson and Simonson 1998, Sarkas 2000, Zhang 2013).

Lignin is a material that is obtained from wastes resulted from delignification process of cacao peel that reacted with formaldehyde resorcinol to be lignin resorcinol formaldehyde adhesive. The objective of this study is to minimize dependence on adhesive demand, to minimize environmental pollution, and also to minimize production cost of adhesive products. This study hopes that the results of this research can be developed in industrial scale in Indonesia which will be able to open up working opportunity for Indonesian society. Due to the important role of lignin in fiberboard manufacture, several studies have investigated the use of lignin as a natural adhesive and the possibility of replacing fibers with lignin. Angles et.al. (2001) tried to use lignin as a natural adhesive in fiberboard manufacture by adding different types of technical lignins. They found that replacing up to $20 \%$ of the fibers with kraft lignin improved the water resistance and mechanical properties of the boards without significantly affecting their density. Subsequently, Velasquez et.al. (2003) studied the use of untreated or unpurified kraft lignin resulting from the kraft pulping process to the steam exploded Miscanthus sinensis. Thus, in this study we try to put lignin from cacao peel with cooking liquid of sodium hydroxide effectively in the process and use chemical agents efficiently and then lignin powder can be used as a material of lignin adhesive production. The resulted adhesive is close to the capacity of commercial adhesive and can be diluted using water.

\section{METHODOLOGY}

The study used cacao peel from International Coffee and Cacao Research Center (ICCRI) in Jember Regency. The variables of this study are: sodium hydroxide concentration (i.e. $8 \%, 10 \%, 12 \%$ and $18 \%)$; with the cooking time of: $(60$, $90,120,180)$ minutes. The weight of cacao peel is $200 \mathrm{~g}$, and oven temperature is $105{ }^{\circ} \mathrm{C}$ during 2-3 hours. We used the extractor, to cook and extract lignin from cacao peel, and dried the lignin in the oven. The cacao peel to be used was cleaned, and cut into small sizes about $0.5-1 \mathrm{~cm}$; it was pounded until a fiber formed, and then dried in the sun. A 
total of $200 \mathrm{~g}$ dried fiber was cooked with water for an hour as the softening process. A sodium hydroxide solution was added to the soft fiber with a variable concentration of (1:5), then cooked appropriately with the variable timing at a temperature of $100 \mathrm{oC}$ to obtain the black liquor; and then it was separated from its pulp by a screening process. The black liquor obtained was diluted with water until $\mathrm{pH}$ was 8-9, and then it was added with HCL $10 \%$ until $\mathrm{pH}$ reached 2-3. The sedimentation process took 8-10 hours, and then it was separated from its liquid. The next step was drying the lignin in an oven at a temperature of $105 \mathrm{oC}$ for 2-3 hours. The dried lignin was pounded until it became a powder ready to use as the material of lignin adhesive. A quantity of $5 \mathrm{~g}$ lignin powder was mixed with $2.5 \mathrm{~g}$ of resorcinol and $10 \mathrm{~mL}$ of formaldehyde solution; then it was agitated continuously and added with $\mathrm{NaOH} 10 \%$ and $60 \%$ (20 mL respectively) until it formed a lignin adhesive.

\section{Testing of the Adhesive capacity of Lignin adhesive}

This study determined the adhesive capacity of lignin adhesive by the following measurement: The wood was cut into two parts of $8 \mathrm{Cm} \times 3 \mathrm{Cm}$ and glued together with the lignin adhesive; with a position of $3 \mathrm{Cm} \times 3 \mathrm{Cm}$. It was then allowed to dry out then was pulled hard until it broke off. The result of the adhesive capacity of the lignin adhesive was $3.54 \mathrm{~kg} / \mathrm{sq} . \mathrm{Cm}$.

\section{Lignin Quantity Determination}

A total of $200 \mathrm{~g}$ of cacao peel was boiled with water in order to soften the cacao peel and then it was screened. The softened cacao peel was then cooked with $1 \mathrm{~L}$ of $\mathrm{NaOH} 10 \%$ for 2 hours. It resulted in $600 \mathrm{~mL}$ of lignin, and then it was diluted with $3 \mathrm{~L}$ of water and it was heated at $60{ }^{\circ} \mathrm{C}$. After that, it was cooled down and the measured $\mathrm{pH}$ was 8-9. Then it was deposited by adding a $300 \mathrm{~mL}$ of sulfate acid. The deposit of lignin was dried in the oven at a temperature of $105^{\circ} \mathrm{C}$ for 24 hours and resulted in $29.8 \mathrm{~g}$ of lignin.

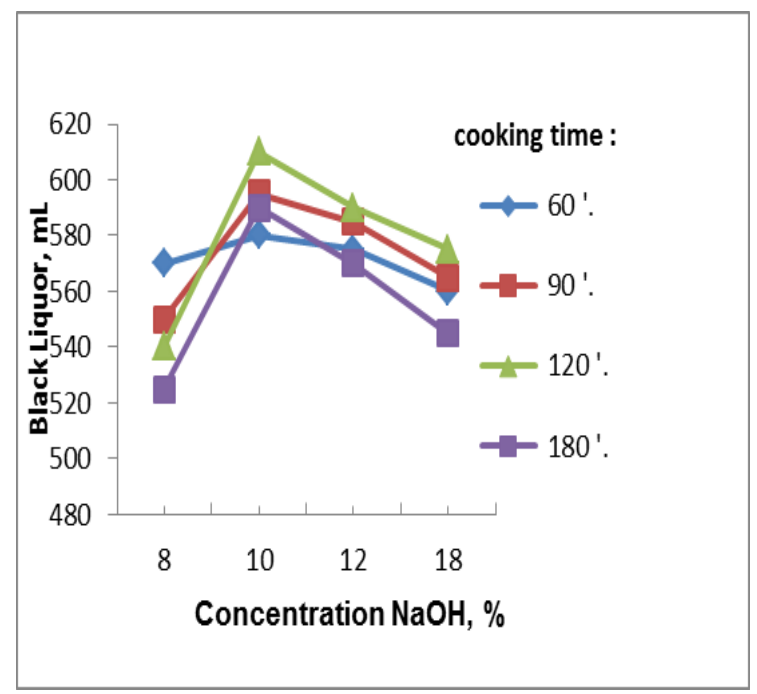

Figure- 1 Effect of $\mathrm{NaOH}$ concentration on black

\section{RESULTS AND DISCUSSIONS}

The results obtained during the study have been analyzed for its density of black liquor and lignin powder quantity.

Table-1. Data of Black Liquor towards Cooking Time and Concentration of $\mathrm{NaOH}$ cooking liquid

\begin{tabular}{|c|c|c|c|}
\hline $\begin{array}{c}\text { Cooking } \\
\text { time, min. }\end{array}$ & $\begin{array}{c}\text { Concentration } \\
\mathrm{NaOH}\end{array}$ & $\begin{array}{c}\text { Black } \\
\text { Liquor }\end{array}$ & $\begin{array}{c}\text { Lignin } \\
\text { Powder }\end{array}$ \\
\hline \multirow{3}{*}{60} & 8 & 570 & 28.3 \\
\cline { 2 - 4 } & 10 & 580 & 28.8 \\
\cline { 2 - 4 } & 12 & 575 & 28.5 \\
\cline { 2 - 4 } & 18 & 560 & 27.8 \\
\hline \multirow{3}{*}{90} & 8 & 550 & 27 \\
\cline { 2 - 4 } & 10 & 595 & 29.5 \\
\cline { 2 - 4 } & 12 & 585 & 29 \\
\hline \multirow{3}{*}{120} & 18 & 565 & 28 \\
\cline { 2 - 4 } & 1 & 540 & 27.8 \\
\cline { 2 - 4 } & 12 & 610 & 29.8 \\
\cline { 2 - 4 } & 18 & 590 & 29.3 \\
\cline { 2 - 4 } & 8 & 525 & 28.5 \\
\cline { 2 - 4 } & 10 & 590 & 26 \\
\cline { 2 - 4 } & 12 & 570 & 28.3 \\
\hline \multirow{3}{*}{180} & 18 & 545 & 27 \\
\hline
\end{tabular}

Based on table 1, the higher the concentration of $\mathrm{NaOH}$ at variations of cooking time, the fewer the black liquor obtained, even though at low concentrations it was increasing. The reason was that the increasing of $\mathrm{NaOH}$ concentration would scatter the lignin in cacao peel. However, in the condition of cooking liquids of $\mathrm{NaOH}$ with higher $\mathrm{pH}$, the lignin will be ionized and salt was formed.

At a concentration of $\mathrm{NaOH} 10 \%$ and cooking time of 120 minutes, as much as $610 \mathrm{~mL}$ black liquor can be obtained, and then we can take its solid lignin.

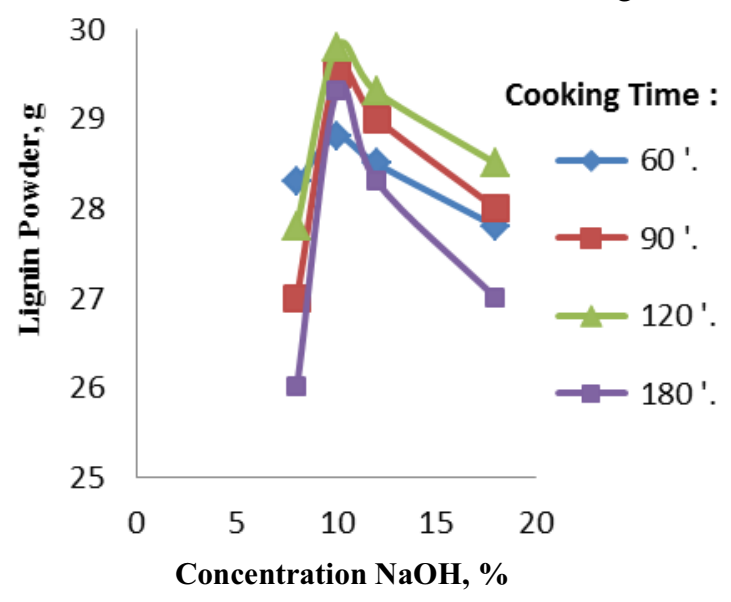

Figure-2. Effect of $\mathrm{NaOH}$ concentration on yield Of lignin

The longer the cooking time at variable concentrations of cooking liquid, the more lignin powder 
to be obtained. The best result can be found at a cooking time of 120 minutes with a concentration of $\mathrm{NaOH} 10 \%$, which was $29.8 \mathrm{~g}$. After that, it will decrease because the longer the cooking time, the lignin separated from cacao peel will be dissolved and mixed with its cacao peel.

Compared to the research from the previous researchers, this study makes it relatively easier to separate lignin from cacao peel by an earlier softening method of cacao peel's material and adjusting $\mathrm{pH}$ of liquid before going to the sedimentation process of lignin with HCL solution $10 \%$. After that, we analyzed the adhesive capacity of the lignin adhesives, and gave a result of $3.54 \mathrm{~kg} / \mathrm{sq} . \mathrm{Cm}$, where the adhesive's color is dark brown, near to cacao peel's color. Compared to the commercial adhesive that possess an adhesive capacity of $3.65 \mathrm{~kg} / \mathrm{sq} . \mathrm{Cm}$, the lignin adhesive produced by this research is nearly equal to the capacity of commercial adhesive. Although the color is still not perfect, we are making progress on it.

\section{CONCLUSIONS}

Black liquor can be obtained from cacao peel and is deposited to lignin powder that is ready for use as a material for adhesives production. The result of lignin powder is $29.8 \mathrm{~g}$ at concentration $\mathrm{NaOH} 10 \%$ and cooking time $120 \mathrm{~min}$. Adhesives capacity of lignin is $3.54 \mathrm{~kg} / \mathrm{sq} . \mathrm{Cm}$, and its color nearly equal to the color of cacao peel.

\section{REFERENCES}

Angles, M.N., Ferrando, F., Farriol, F, X., Salvado, J.,2001. "Suitability of steam exploded residual softwood for the production of binderless panels. Effect of the pretreatment severity and lignin addition, Biomass \& Bioenergy, 21(3), 211-224.

Danielson, B., Simonson, R., 1989. Kraft lignin in phenol formaldehyde resin. Part I. Partial replacement of phenol by kraft lignin in phenol formaldehyde adhesive for plywood. Journal of Adhesion Science and Technology 12:923-936

Hemalia, V., Trisschler, J., Sandberg, D., 2013. Lignin An Adhesive raw material of the future or waste of research energy. Brischke, C. \& Mayer, L.(Eds,) Proc. $9^{\text {th }}$ Meeting of the Northern European Network for wood Science and Engineering (WSE), (pp.98-103) Hannover, Germany, September 11-12,2013.

Helio Faustino, Nuno Gil, Cecilia Baptista and Ana Paula Duarte, 2010. Antioxidant Activity of Lignin Phenolic Compounds Extracted from Kraft and Sulphite Black Liquors. Molecules 2010,15, 93089322;doi:10.3390/molecules 15129308 .

Hu, L., Pan, H., Zhou, Y., Zhang, M., 2011. Methods to improve lignin's reactivity as a phenol substitute an as a replacement for other phenolic compounds: a brief review. BioResources 6(3).
Imam, S.H., Gordon, S.H., Mao, L., Chen, L., 2001. Environmentally friendly wood adhesive from a renewable plant polymer: Characteristics and optimization. Polymer Degradation and Stability 73:529533.

Mawardi, 2009. "Quality of Particle Board from Palm Coconut Wood Based on Polystyrene, Adhesive , Journal of Machine Engineering, 11 (2) 91-96.

Mankar S.S, Chaudhari, A.R. \& Soni, I.2012. Lignin in phenol-formaldehyde adhesives. International Journal of Knowledge Engineering 3:116-118.

Nihat Sami CETIN, Nilgul OZMEN, 2003. Studies on Lignin-Based Adhesives for Particleboard Panels.Turk J Agric For 27 (2003) 183-189@ TUBITAK.

Pizzi, A. 2006. Recent development in eco-efficient biobased adhesives for wood bonding: opportunities and issues. Journal of Adhesives Science and Technology 20:829-846.

Sarkar, S., Adhikari, B., 2000. Lignin-modified phenolic resin: synthesis optimization, adhesive strength, and thermal stability. Journal of Adhesion Science and Technology, 14(9):1179-1193.

Rowel, R.M.,2012. Hand Book of wood chemistry and wood composites. Bio-based adhesives.CRC Press.

Velasquez, J.A., Ferrando, F., Farriol, X., and Salvado, J.,2003. " Binderless Fiberboard from Steam exploded Miscanthus sinensis, Wood Science and Technology 37 (34), 269-302.

Yao Chen, CharlesR. Frihart, Zhiyong Cai, Linda F. Lorenz, Nocole M, Stark, 2013. Lignin-based PhenolFormaldehyde Resins from Purified $\mathrm{CO}_{2}$ Precipitated Kraft Lignin $\left(\mathrm{PCO}_{2} \mathrm{KL}\right)$. International Conference on Wood Adhesives, page 601. U.S. Departement of Agriculter, Forest Service, Forest Product Laboratory, One Giffort PinchotDrive, Madison, WI53726-2398, United State.

Zhang, W., Ma, Y., Wang, C., Li, S., Zhang, M., Chu, F., 2013. Preparation and properties of lignin-formaldehyde resins based on different biorefinery residues of agricultural biomass. Industrial Crops and Products 43:326-333. 